\title{
Genetic Diversity in Roselle (Hibiscus sabdariffa L.) for Fiber Yield Traits in North Coastal Zone of Andhra Pradesh, India
}

\author{
N. Hari Satyanarayana ${ }^{1 *}$, V. Visalakshmi ${ }^{2}$, J. Jagannadham ${ }^{1}$, K. Madhu Kumar ${ }^{2}$, \\ P. Amarajyothi ${ }^{1}$, A. Upendra Rao ${ }^{2}$, K.V. Ramana Murthy ${ }^{3}$ and N. Venugopala Rao ${ }^{3}$ \\ ${ }^{1}$ Agricultural Research Station, Amadalavalasa, Srikakulam District, A. P. - 532 185, India \\ ${ }^{2}$ Agricultural Research Station, Ragolu, Srikakulam District, A. P. - 532 484, India \\ ${ }^{3}$ Regional Agricultural Research Station (North Coastal Zone), Anakapalle, \\ A.P. - 531 001, India \\ *Corresponding author
}

\begin{tabular}{|c|c|}
\hline & A B S T R A C T \\
\hline & \multirow{6}{*}{$\begin{array}{l}\text { Sixty genotypes of roselle (Hibiscus sabdariffa L.) were evaluated in North Coastal zone } \\
\text { of Andhra Pradesh at Agricultural Research Station, Ragolu for fiber yield and eleven } \\
\text { contributing characters during Kharif, } 2013 \text { \& } 2014 \text { and grouped them into six clusters } \\
\text { based on D } \mathrm{D}^{2} \text { analysis. Cluster I comprised of fifty one genotypes followed by Cluster II, } \\
\text { III, IV and V with two genotypes each and the Cluster VI with a solitary genotype. Inter- } \\
\text { cluster distance was highest between the Clusters V and III followed by Clusters V and VI } \\
\text { and Clusters V and II; whereas Intra-cluster distance was high for Cluster I which consists } \\
\text { of maximum number of genotypes followed by Cluster V. Cluster III recorded highest and } \\
\text { high mean values for fiber yield and its attributing traits like dry stick weight, green } \\
\text { weight, green weight (leafless), plant height, base diameter, mid diameter and bark } \\
\text { thickness, whereas, Cluster V recorded lowest and low mean values for most of the fiber } \\
\text { yield contributing traits. Fiber yield contributed high for the diversity followed by dry stick } \\
\text { weight, green weight, plant height and green weight (leafless). The genotypes belonging to } \\
\text { Cluster II, III, V and VI could be selected as parents in future breeding programme for } \\
\text { developing high fiber yielding varieties. }\end{array}$} \\
\hline Keywords & \\
\hline $\begin{array}{l}\text { Cluster distance, } \\
\text { Fiber yield, Genetic } \\
\text { divergence, Roselle. }\end{array}$ & \\
\hline Article Info & \\
\hline $\begin{array}{l}\text { Accepted: } \\
23 \text { August } 2017 \\
\text { Available Online: } \\
\text { 10 September } 2017\end{array}$ & \\
\hline & \\
\hline
\end{tabular}

\section{Introduction}

Roselle (Hibiscus sabdariffa L.) is an annual or perennial plant belonging to the large family Malvaceae and is cultivated in Tropical and Sub-Tropical regions for bast fiber, paper pulp or edible calyces, leaves and seeds (Osman et. al., 2011). In India, roselle is one of the most important bast fiber crops which occupies second place in area and production after jute and is mainly used for manufacturing of sacs, twines, carpets etc. (Satyanarayana et al., 2015).
In India, the major growing states of roselle crop are Andhra Pradesh, Bihar, Orissa, West Bengal and Maharastra with an area of 84 thousand ha (during 2012-13) that produced 6.16 lakh bales (1bale $=180 \mathrm{~kg}$ ) with an average productivity of about $13.20 \mathrm{q} / \mathrm{ha}$ (Sen and Karmakar, 2014). Raw jute, the fiber of commerce is extracted from the stem of two cultivated species of jute (tossa \& white jute) and mesta (roselle \& kenaf). Raw jute (jute and mesta) occupying only $0.55 \%$ of the 
cropped area of the country provide livelihood support to 4 million farm families, 0.25 million industrial workers and 0.50 million traders in India. India is the major grower of roselle in world (Mahapatra, 2013).

In crop improvement programme, to increase the productivity breeder needs to maintain a pool of diverse desirable donor parents (Joshi et al., 2013). An apparent understanding of genetic diversity is essential for the effective conservation and utilization of genetic resources. Presence of sufficient genetic diversity is a pre-requisite to formulate breeding programme aimed at improvement in yield and other characters, since the crosses made between the parents with maximum genetic divergence would more likely to yield desirable recombinants in the progeny. Further, selection of diverse parents for hybridization programme will be effective by the identification of characters responsible for the total genetic diversity among the populations (Murthy and Arunachalam, 1966). In this context, Mahalanobis $D^{2}$ statistic is an effective tool in quantifying the degree of divergence at genetic level and it also provides quantitative measure of association between geographic and genetic diversity based on generalized distance (Mahalanobis, 1936).

\section{Materials and Methods}

Sixty roselle (Hibiscus sabdariffa L.) genotypes consisting of eleven exotic lines; four released varieties and 45 indigenous accessions (Table-1) were evaluated in North Coastal zone, Andhra Pradesh at Agricultural Research Station, Ragolu (Latitude $18^{\circ} 24^{\prime} \mathrm{N}$; Longitude $83.84^{\circ} \mathrm{E}$ at an altitude of $27 \mathrm{~m}$ above mean sea level) during early kharif seasons of 2013 and 2014. The experimental trial was laid out in randomized block design with a plot size of four rows of $2 \mathrm{~m}$ length in two replications with a spacing of $30 \times 10 \mathrm{~cm}$ under rainfed conditions. Recommended package of practices was followed to raise a good crop. Data on the basis of five randomly selected competitive plants were recorded on plant height $(\mathrm{cm})$, base diameter $(\mathrm{mm})$, mid diameter $(\mathrm{mm})$, top diameter $(\mathrm{mm})$, internodal length $(\mathrm{cm})$, petiole length $(\mathrm{cm})$, number of nodes, bark thickness $(\mathrm{mm})$, green weight $(\mathrm{g})$, green weight (leafless) (g), dry stick weight (g) and fiber yield (g). Genetic diversity analysis was done as per Mahalanobis $\mathrm{D}^{2}$ statistic described by Rao (1952) and the genotypes were grouped into different clusters utilizing Tocher's method.

\section{Results and Discussion}

The analysis of variance revealed significant differences among sixty genotypes for all the twelve characters under study which indicated the existence of significant amount of variability among the sixty genotypes for all the characters. On the basis of Mahalanobis $\mathrm{D}^{2}$ analysis, sixty genotypes were grouped into six clusters based on twelve fiber yield attributing traits viz., plant height, base diameter, mid diameter, top diameter, internodal length, petiole length, number of nodes, bark thickness, green weight, green weight (leafless), dry stick weight and fiber yield. The clusters were formed on the basis of average cluster distance, following Tocher's method considering fiber yield and its attributing traits (Table 2). The Cluster I comprised of fifty one genotypes followed by Cluster II, III, IV and V comprising of two genotypes each and the Cluster VI consists of a single genotype. Earlier, Anuradha (2003) grouped 68 roselle genotypes into eleven clusters; Shobha and Dharmatti (2004) grouped twenty six kenaf lines into five clusters; Pulli Bai et al., (2005) grouped 51 roselle genotypes into seven clusters; Hariram et al., (2013) grouped sixty genotypes of roselle into nine clusters; Asha et al., (2015) grouped 49 genotypes of okra into eight 
clusters; Kurrey et al., (2015) grouped twenty five chench genotypes into five groups; Satyanarayana et al., (2015) grouped sixty genotypes into seven clusters; Jyothsna and Satyanarayana (2016) grouped 30 genotypes of roselle into six clusters and Pandey et al., (2017) grouped 143 genotypes of wheat into twelve clusters. The genotypes of same geographical origin were grouped into different clusters indicating that geographical diversity though important may not necessarily be the only factor in determining the genetic diversity.

The results obtained through classification of genotypes using $\mathrm{D}^{2}$ statistics would provide a set of groups from which desirable parents may be selected for further breeding programme with respect to fiber yield attributing characters in general and the trait fiber yield in particular. Considering the $\mathrm{D}^{2}$ values (Table 3), it was noticed that the values varied from 11.270 to 372.496 . Maximum inter cluster distance was observed between Cluster V and III (372.496) followed by Cluster V and VI (255.884) and Cluster V and
II (218.315). The intra-cluster $\mathrm{D}^{2}$ values ranged from 11.270 to 86.168 , Cluster I showed the maximum intra-cluster $D^{2}$ value (86.168) followed by Cluster V (81.218) and Cluster IV (32.354). Wide genetic distance was evident among the genotypes of different groups than those within the same cluster. The higher inter-cluster distance between Cluster V with Cluster III followed by Cluster VI and Cluster II indicated that the genotypes belonging to Cluster $\mathrm{V}$ were widely distanced genetically from those of Cluster III, VI and II. In other words, genotypic constituent of these cluster pairs comprised the genes in respect of the characters which may help to breed desirable lines with high fiber yield. Minimum inter-cluster $\mathrm{D}^{2}$ values were observed between Cluster II and VI (25.591) followed by Cluster III and VI (42.375) which indicated that genotypes of Clusters II and VI; III and VI were more or less closely related. It could be predicted that the genotypes belonging to different clusters separated by high estimated statistical distance could be used in hybridization programme to develop high fiber yielding segregants.

Fig.1 Percent contribution of fiber yield attributing traits towards diversity in roselle

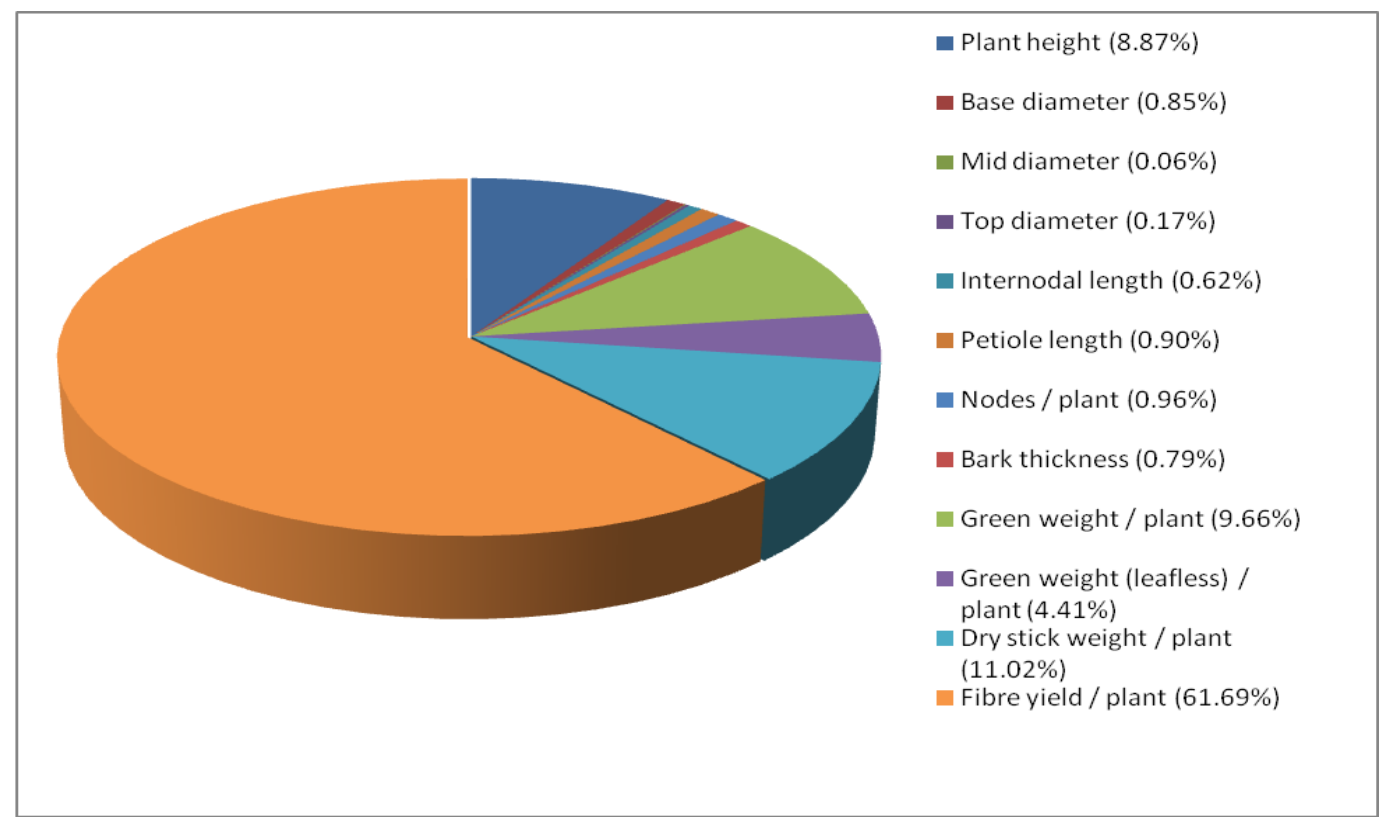


Table.1 List of sixty roselle (Hibiscus sabdariffa L.) genotypes

\begin{tabular}{|c|l|}
\hline Type of genotype & \multicolumn{1}{|c|}{ Name of the genotypes } \\
\hline & AR-14, AR-19, AR-42, AR-45, AR-48, AR-50, AR-55, AR-66, AR-67, \\
& AR-71, AR-79, AR-80, AR-81, AR-85, AR-88, R-16, R-29, R-30, R-37, \\
Indigenous (45) & R-48, R-67, R-68, R-77, R-86, R-134, R-180, R-225, R-243, R-271, R- \\
& 284, R-318, R-322, AS-80-6, AS-80-7, AS-80-19, AS-80-26, AS-80-29, \\
& AS-81-1, AS-81-2, AS-81-3, AS-81-5, AS-81-9, AS-81-14, AS-81-17 \\
& and AS-81-22 \\
\hline \multirow{2}{*}{ Exotic (11) } & ER-56, ER-57, ER-60, ER-68, REX-6, REX-14, REX-34, REX-38, REX- \\
\hline Varieties (4) & H5, REX-52 and REX-63 \\
\hline
\end{tabular}

Table. 2 Grouping of sixty roselle genotypes into clusters based on fiber yield attributing traits

\begin{tabular}{|c|l|c|l|}
\hline Sl. No. & Cluster & No. of genotypes & \multicolumn{1}{c|}{ Name of genotypes } \\
\hline & & & AR-14, AR-19, AR-42, AR-45, AR-48, AR-50, AR-55, \\
& & & AR-66, AR-67, AR-71, AR-79, AR-80, AR-81, AR-85, \\
& & & AR-88, R-16, R-29, R-30, R-37, R-48, R-67, R-68, R-77, \\
1. & Cluster I & $\mathbf{5 1}$ & R-86, R-134, R-180, R-225, R-243, R-271, R-284, R-318, \\
& & & R-322, AS-80-6, AS-80-7, AS-80-19, AS-80-26, AS-80-29, \\
& & & AS-81-1, AS-81-2, AS-81-3, AS-81-5, AS-81-9, AS-81-14, \\
& & & AS-81-17, AS-81-22, ER-56, ER-57, ER-60, ER-68, REX- \\
& & & 6 and REX-14 \\
\hline $\mathbf{2 .}$ & Cluster II & $\mathbf{2}$ & AMV-4 and AMV-5 \\
\hline $\mathbf{3 .}$ & Cluster III & $\mathbf{2}$ & REX-52 and HS-4288 \\
\hline $\mathbf{4 .}$ & Cluster IV & $\mathbf{2}$ & REX-52 and REX-63 \\
\hline $\mathbf{5 .}$ & Cluster V & $\mathbf{2}$ & REX-34 and REX-38 \\
\hline $\mathbf{6 .}$ & Cluster VI & $\mathbf{1}$ & AMV-7 \\
\hline
\end{tabular}

Table.3 Inter-cluster and Intra-cluster D-square values for fiber yielding traits in Sixty genotypes of roselle

\begin{tabular}{|c|c|c|c|c|c|c|}
\hline Cluster & $\begin{array}{c}\text { Cluster - } \\
\text { I }\end{array}$ & $\begin{array}{c}\text { Cluster - } \\
\text { II }\end{array}$ & $\begin{array}{c}\text { Cluster - } \\
\text { III }\end{array}$ & $\begin{array}{c}\text { Cluster - } \\
\text { IV }\end{array}$ & $\begin{array}{c}\text { Cluster - } \\
\text { V }\end{array}$ & $\begin{array}{c}\text { Cluster - } \\
\text { VI }\end{array}$ \\
\hline Cluster - I & $\mathbf{8 6 . 1 6 8}$ & $\mathbf{5 5 . 8 2 4}$ & $\mathbf{1 2 1 . 3 7 1}$ & $\mathbf{6 2 . 4 9 1}$ & $\mathbf{1 8 6 . 3 7 7}$ & $\mathbf{6 9 . 6 3 4}$ \\
\hline Cluster - II & & $\mathbf{1 1 . 2 7 0}$ & $\mathbf{7 3 . 0 2 5}$ & $\mathbf{4 4 . 1 5 3}$ & $\mathbf{2 1 8 . 3 1 5}$ & $\mathbf{2 5 . 5 9 1}$ \\
\hline Cluster - II & & & $\mathbf{2 9 . 3 2 3}$ & $\mathbf{8 7 . 1 0 2}$ & $\mathbf{3 7 2 . 4 9 6}$ & $\mathbf{4 2 . 3 7 5}$ \\
\hline Cluster - IV & & & & $\mathbf{3 2 . 3 5 4}$ & $\mathbf{1 5 4 . 5 0 1}$ & $\mathbf{4 5 . 7 0 0}$ \\
\hline Cluster - V & & & & & $\mathbf{8 1 . 2 1 8}$ & $\mathbf{2 5 5 . 8 8 4}$ \\
\hline Cluster - VI & & & & & & $\mathbf{0 . 0 0 0}$ \\
\hline
\end{tabular}


Table.4 Cluster mean values for twelve fiber yield attributing traits in sixty genotypes of roselle

\begin{tabular}{|c|c|c|c|c|c|c|c|c|c|c|c|c|}
\hline Cluster & $\begin{array}{c}\text { Plant } \\
\text { height } \\
(\mathrm{cm})\end{array}$ & $\begin{array}{c}\text { Base } \\
\text { diameter } \\
(\mathrm{mm})\end{array}$ & $\begin{array}{c}\text { Mid } \\
\text { diameter } \\
(\mathrm{mm})\end{array}$ & $\begin{array}{c}\text { Top } \\
\text { diameter } \\
(\mathrm{mm})\end{array}$ & $\begin{array}{l}\text { Internodal } \\
\text { length } \\
(\mathrm{cm})\end{array}$ & $\begin{array}{l}\text { Petiole } \\
\text { length } \\
(\mathrm{cm})\end{array}$ & $\begin{array}{l}\text { Nodes } \\
\text { / plant }\end{array}$ & $\begin{array}{c}\text { Bark } \\
\text { thickness } \\
(\mathrm{mm})\end{array}$ & $\begin{array}{c}\text { Green } \\
\text { weight } \\
\text { / plant }\end{array}$ & $\begin{array}{c}\text { Green } \\
\text { weight } \\
\text { (leafless) } \\
\text { / plant }\end{array}$ & $\begin{array}{c}\text { Dry } \\
\text { stick } \\
\text { weight } \\
\text { / plant }\end{array}$ & $\begin{array}{c}\text { Fiber } \\
\text { yield / } \\
\text { plant } \\
(\mathrm{g})\end{array}$ \\
\hline Cluster - I & 309.68 & 19.23 & 13.82 & 9.49 & 5.64 & 10.72 & 67.28 & 1.95 & 525.15 & 249.81 & 54.80 & 22.20 \\
\hline Cluster - II & 338.29 & 19.74 & 14.38 & 9.80 & 5.92 & 9.28 & 67.13 & 1.80 & 503.00 & 220.53 & 58.69 & 21.74 \\
\hline Cluster - III & 332.85 & 20.50 & 14.54 & 10.10 & 5.80 & 10.13 & 68.38 & 2.15 & 604.78 & 289.76 & 75.99 & 32.57 \\
\hline Cluster - IV & 293.13 & 19.00 & 13.56 & 9.42 & 5.37 & 9.49 & 66.75 & 2.05 & 535.05 & 217.37 & 50.48 & 24.23 \\
\hline Cluster - V & 218.07 & 18.18 & 13.23 & 9.37 & 4.81 & 11.13 & 64.00 & 2.14 & 405.53 & 143.75 & 27.41 & 13.42 \\
\hline Cluster - VI & 348.32 & 22.65 & 13.83 & 9.67 & 5.53 & 9.44 & 73.00 & 2.34 & 594.20 & 272.00 & 65.92 & 26.97 \\
\hline
\end{tabular}


Table.5 Percent contribution of fiber yielding traits for genetic diversity in Sixty genotypes of roselle

\begin{tabular}{|l|c|c|}
\hline \multicolumn{1}{|c|}{ Name of the character } & Times Ranked 1st & Contribution \% \\
\hline Plant height $(\mathrm{cm})$ & 157 & 8.87 \\
\hline Base diameter $(\mathrm{mm})$ & 15 & 0.85 \\
\hline Mid diameter $(\mathrm{mm})$ & 1 & 0.06 \\
\hline Top diameter $(\mathrm{mm})$ & 3 & 0.17 \\
\hline Internodal length $(\mathrm{cm})$ & 11 & 0.62 \\
\hline Petiole length $(\mathrm{cm})$ & 16 & 0.90 \\
\hline Nodes / plant & 17 & 0.96 \\
\hline Bark thickness (mm) & 14 & 0.79 \\
\hline Green weight / plant & 171 & 9.66 \\
\hline Green weight (leafless) / plant & 78 & 4.41 \\
\hline Dry stick weight / plant & 195 & 11.02 \\
\hline Fiber yield / plant (g) & 1092 & 61.69 \\
\hline \multicolumn{1}{r|}{ Total } & $\mathbf{1 7 7 0}$ & $\mathbf{1 0 0 . 0 0}$ \\
\hline
\end{tabular}

Variations in mean values for different characters were observed among different clusters (Table 4). Among twelve characters studied, Cluster III recorded highest and high mean values for fiber yield and its attributing traits like dry stick weight, green weight, green weight (leafless), plant height, base diameter, mid diameter and bark thickness, whereas, Cluster V recorded lowest and low mean values for most of the fiber yield contributing traits. Cluster I has recorded medium range mean values for most of the traits as it consists of highest number of genotypes thereby the mean values come down generally.

Cluster VI which was a solitary genotype recorded high values for most of the fiber yielding traits. Cluster II recorded high to medium range mean values for most of the traits, whereas, Cluster IV recorded medium to low values. Per cent contribution of individual characters towards (Table 5 and Fig. 1) total genotypic divergence in sixty genotypes under study was found highest by fiber yield (61.69\%) and it was followed by dry stick weight $(11.02 \%)$, green weight $(9.66 \%)$, plant height $(8.87 \%)$, green weight (leafless) $(4.41 \%)$ and the other characters contributed less than $1 \%$ towards total divergence. The results of the present study were in close agreement with the findings of Hariram et al., (2013) in roselle, Asha et al., (2015) in okra, Satyanarayana et al., (2015) in roselle and Jyothsna and Satyanarayana (2016) in roselle.

Considering the results obtained from the cluster distances and mean values, the genotypes belonging to Cluster V, III, VI and II viz., REX-34, REX-38, REX-52, HS-4288, AMV-7, AMV-4 and AMV-5 could be selected as parents in future breeding programme for improvement in fiber yield of roselle.

\section{Acknowledgement}

The authors are highly thankful to the authorities of ANGRAU, Andhra Pradesh for providing necessary help and infrastructural facilities to undertake this study. 


\section{References}

Anuradha, T., 2003. Genetic divergence in roselle (Hibiscus sabdariffa L.). J. Res. ANGRAU. 31 (2): 122-126.

Asha, I. S., Bhaganna, H., Gangaprasad, S., Netravati and Salimath, P. M. 2015. Analysis of genetic divergence in okra [Abelmoschus esculentus (L.) Moench]. The Ecoscan. 7(S): 35-39.

Hariram, K. B., Appalaswamy, A., Durga Prasad, A. V. S and Ismail, S. 2013. Genetic divergence studies in roselle (Hibiscus sabdariffa L.). Madras Agric. J. 100(1-3): 20-22.

Joshi, M., Verma, S. K., Singh, J. P. and Barh, A. 2013. Genetic diversity assessment in lentil (Lens culinaris Medikus) genotypes through ISSR marker. The Bioscan. 8(4): 1529-1532.

Jyothsna, S., and Satyanarayana, N. H. 2016. Genetic divergence studies for fiber yield and its contributing traits in Roselle (Hibiscus sabdariffa L.). Vegetos 29(3): 156-157

Kurrey, V. V., Sharma, P. K., Dixit, A. and Ramteke, V. 2015. Estimation of genetic divergence among chench (Corchorus acutangulus LAM.) genotypes. The Ecoscan. 7(S): 319-323.

Mahalanobis, P. C., 1936. On the generalized distance in statistics. Proceedings of National Institute of Science (India), 12: 49-55.

Mahapatra, B. S., 2013. Research on Jute and Allied Fiber crops: Present status and future perspective (in) Souvenir: National Symposium on Jute and Allied Fibers in Changing times Issues and Strategies held on 3-5, January, 2013 at NIRJAFT, Kolkata. pp. $20-29$

Murthy, B. R., and Arunachalam, V. 1966. The nature of divergence in relation to breeding system in crop plants. Indian J. Genet. 26: 188-198.

Osman, M., Faruq, G., Saberi, S., Majid, N. A., Nagoor, N. H. and Zulqarnain, M. 2011. Morpho-agronomic analysis of three roselle (Hibiscus sabdariffa L.) mutants in tropical Malaysia. Australian J. Crop Sci. 5(10): 1150-1156.

Pandey, M. K., Bind, H. N., Sanjeev Kumar and Singh, B. N. 2017. Genetic Divergence in Wheat (Triticum aestivum L. Thell.) under Saline Sodic Condition. Int. J. Curr. Microbiol. App. Sci. 6(5): 181-189.

Pulli Bai, P., Razia Sultana, Panduranga Rao, C and Srinivasa Rao, V. 2005. Multivariate analysis in roselle hemp (Hibiscus sabdariffa L.). The Andhra Agric. J. 52 (1\&2): 86-92.

Rao, C. R., 1952. Advance statistical methods in biometric research. John Wiley and Sons, New York, pp 328.

Satyanarayana, N. H., Mukherjee, S., Roy, S., Bhanu Priya, Sarkar, K. K. and Bandhopadhyay, P. 2015. Genetic divergence studies for fiber yield traits in roselle (Hibiscus sabdariffa L.) in Terai zone of West Bengal. J. Crop and Weed 11(S): 9094.

Sen, H. S., and Karmakar, P. G. 2014. PublicPrivate Partnership from the perspectives of CRIJAF for development of Jute and Allied Fibers (in) Today's natural fibers for tomorrow. International Conference on Natural Fibers, held on 1-3 August, 2014 organized by The Indian Natural Fiber Society, Kolkata pp. 40-44.

Shobha, S., and Dharmatti, P. R. 2004. Genetic divergence in vegetable Mesta. Karnataka J. Agric. Sci. 17(2): 275-278.

\section{How to cite this article:}

Hari Satyanarayana, N., V. Visalakshmi, J. Jagannadham, K. Madhu Kumar, P. Amarajyothi, A. Upendra Rao, K.V. Ramana Murthy and Venugopala Rao, N. 2017. Genetic Diversity in Roselle (Hibiscus sabdariffa L.) for Fiber Yield Traits in North Coastal Zone of Andhra Pradesh, India. Int.J.Curr.Microbiol.App.Sci. 6(9): 2335-2341. doi: https://doi.org/10.20546/ijcmas.2017.609.286 